\title{
How much physical activity is enough to prevent unhealthy weight gain? Outcome of the IASO 1st Stock Conference and consensus statement
}

Citation for published version (APA):

Saris, W. H. M., Blair, S. N., van Baak, M. A., Eaton, S. B., Davies, P. S., Di Pietro, L., Fogelholm, M., Rissanen, A., Schoeller, D., Swinburn, B., Tremblay, A., Westerterp, K. R., \& Wyatt, H. (2003). How much physical activity is enough to prevent unhealthy weight gain? Outcome of the IASO 1st Stock Conference and consensus statement. Obesity Reviews, 4(2), 101-114. https://doi.org/10.1046/j.1467789X.2003.00101.x

Document status and date:

Published: 01/01/2003

DOI:

10.1046/j.1467-789X.2003.00101.x

Document Version:

Publisher's PDF, also known as Version of record

\section{Document license:}

Taverne

Please check the document version of this publication:

- A submitted manuscript is the version of the article upon submission and before peer-review. There can be important differences between the submitted version and the official published version of record.

People interested in the research are advised to contact the author for the final version of the publication, or visit the DOI to the publisher's website.

- The final author version and the galley proof are versions of the publication after peer review.

- The final published version features the final layout of the paper including the volume, issue and page numbers.

Link to publication

\footnotetext{
General rights rights.

- You may freely distribute the URL identifying the publication in the public portal. please follow below link for the End User Agreement:

www.umlib.nl/taverne-license

Take down policy

If you believe that this document breaches copyright please contact us at:

repository@maastrichtuniversity.nl

providing details and we will investigate your claim.
}

Copyright and moral rights for the publications made accessible in the public portal are retained by the authors and/or other copyright owners and it is a condition of accessing publications that users recognise and abide by the legal requirements associated with these

- Users may download and print one copy of any publication from the public portal for the purpose of private study or research.

- You may not further distribute the material or use it for any profit-making activity or commercial gain

If the publication is distributed under the terms of Article $25 \mathrm{fa}$ of the Dutch Copyright Act, indicated by the "Taverne" license above, 


\title{
How much physical activity is enough to prevent unhealthy weight gain? Outcome of the IASO 1st Stock Conference and consensus statement
}

\author{
W. H. M. Saris ${ }^{1}$, S. N. Blair², M. A. van Baak, S. B. Eaton³, P. S. W. Davies', L. Di Pietro ${ }^{5}$, M. Fogelholm6,
} A. Rissanen ${ }^{7}$, D. Schoeller ${ }^{8}$, B. Swinburn ${ }^{9}$, A. Tremblay ${ }^{10}$, K. R. Westerterp ${ }^{1}$ and H. Wyatt ${ }^{11}$

${ }^{1}$ Nutrition and Toxicology Research Institute Maastricht NUTRIM, University of Maastricht, Department of Human Biology, Maastricht, the Netherlands; ${ }^{2}$ Cooper Institute, Dallas, TX, USA; ${ }^{3}$ Department of Anthropology and Radiology, Emory University, Atlanta, GA, USA; ${ }^{4}$ Department of Paediatrics and Child Health, University of Queensland, Royal Children's Hospital, Herston, Brisbane, Australia; ${ }^{5}$ The John B Pierce Laboratory, Yale University, New Haven, CT, USA; ${ }^{6}$ The UKK Institute for Health Promotion Research, Tampere, Finland;

${ }^{7}$ Obesity Research Unit, Helsinki University Hospital, Helsinki, Finland; ${ }^{8}$ Nutritional Sciences, University of Wisconsin, Madison, WI, USA; ${ }^{9}$ Physical Activity and Nutrition Research Unit, School of Health Sciences, Deakin University, Burwood, Victoria, Australia; ${ }^{10}$ Physical Activity Sciences Laboratory, Division of Kinesiology, PEPS, Laval University, Quebec, Canada; ${ }^{11}$ University of Colorado Health Sciences Center, Center for Human Nutrition, Denver, CO, USA Received 17 February 2003; accepted 24 February 2003

Address reprint requests to: WHM Saris, University of Maastricht, Department of Human Biology, PO Box 616, 6200 MD Maastricht, the Netherlands. E-mail: w.saris@hb.unimaas.nl

\begin{abstract}
Summary
A consensus meeting was held in Bangkok, 21-23 May 2002, where experts and young scientists in the field of physical activity, energy expenditure and bodyweight regulation discussed the different aspects of physical activity in relation to the emerging problem of obesity worldwide. The following consensus statement was accepted unanimously.

'The current physical activity guideline for adults of 30 minutes of moderate intensity activity daily, preferably all days of the week, is of importance for limiting health risks for a number of chronic diseases including coronary heart disease and diabetes. However for preventing weight gain or regain this guideline is likely to be insufficient for many individuals in the current environment. There is compelling evidence that prevention of weight regain in formerly obese individuals requires 60-90 minutes of moderate intensity activity or lesser amounts of vigorous intensity activity. Although definitive data are lacking, it seems likely that moderate intensity activity of approximately 45 to 60 minutes per day, or 1.7 PAL (Physical Activity Level) is required to prevent the transition to overweight or obesity. For children, even more activity time is recommended. A good approach for many individuals to obtain the recommended level of physical activity is to reduce sedentary behaviour by incorporating more incidental and leisure-time activity into the daily routine. Political action is imperative to effect physical and social environmental changes to enable and encourage physical activity. Settings in which these environmental changes can be implemented include the urban and transportation infrastructure, schools, and workplaces.'
\end{abstract}

Keywords: Obesity, physical activity, weight gain, weight maintenance.

obesity reviews (2003) 4, 101-114

\section{Introuction}

A decline in daily physical activity levels (PALs) is clearly a major factor contributing to the current obesity epidemic affecting both developed and developing countries in the world. This emerging problem is associated with increasing morbidity and mortality and reduced psychosocial health. Thus, increasing physical activity (PA) has become an important part in public health strategies to prevent weight gain in the first place. Physical activity also plays a pivotal role in the weight maintenance or body-weight regain problem. 
The overall challenge in the battle against the rising levels of obesity is to better understand the modifiable determinants of PA and to translate this knowledge into practical actions for a general public health benefit as well as for the individual to keep a healthy body weight.

A very central and crucial question in this discussion is: 'How much physical activity is enough to prevent unhealthy weight gain or regain?' In the past, a number of consensus meetings have been held and reports published on topics related to this issue $(1,2,3)$. However, these meetings were not specifically focused on the role of PA in this obesity/ body-weight gain issue. In 1995 the US Centers for Disease Control and Prevention and the American College of Sports Medicine published public health recommendations for PA (4). The principal recommendation for sedentary adults was to: 'accumulate 30 minutes or more of moderate-intensity physical activity on most, preferably all days of the week'. This recommendation was confirmed in the US Surgeon General's report and US National Institutes of Health consensus report, both published in 1996, $(5,6)$ and is now generally accepted as the PA guideline for the public. This is probably an adequate dose of activity for general health promotion and disease prevention. However, since these reports were published, several experts have questioned whether this recommendation is sufficient to prevent unhealthy weight (re)gain. Very recently, after the Bangkok meeting, the US Institute of Medicine (IOM) released a report on the new dietary recommendations in which the IOM panel recommended 60 min of moderate-intensity PA for weight maintenance (7). The report focused on diet and nutrition guidelines to meet the body's daily energy and nutritional needs while minimizing the risk of weight gain and to achieve the full health benefits of PA.

This dispute about recommended levels of PA in relation to body-weight regulation was the basis for the first Stock Conference. In commemoration of professor Mike Stock's important scientific contribution to the understanding and treatment of the problem of obesity, the IASO initiated the Stock Conference series, where experts in this field as well as young scientists could meet to discuss a topic of importance for the obesity field in detail. The first Stock Conference was held in Bangkok, Thailand, from 23 to 25 March 2002. The aim of the conference was to review existing evidence on the question and to develop a consensus statement around the central theme: 'How much physical activity is enough to prevent unhealthy weight (re)gain?'

\section{Physical activity from an evolutionary perspective}

In order to judge the PALs in the modern world, it is of interest to get a better insight into the PA experience of our Palaeolithic ancestors. Eaton reviewed the available data on PA and energy balance (8).
Prominent evolutionary theorists, geneticists, biologists, ecologists and anthropologists concur that the contemporary human genome has changed only minimally since behaviourally modern humans appeared something over 50000 years ago. The 10 millennia since agriculture have afforded ample time for genetic adaptation, but if significant changes had been produced by 'civilization', there should be systematic genetic differences between peoples who, like ancestral humans, lived as hunter-gatherers until the last few centuries (e.g. Australian aborigines, African San, arctic Inuit) and peoples whose ancestors adopted agriculture far in the past (e.g. New Easterners, New Guineans, Mayans). No such differences have been discovered.

Evolution occurs through differential reproductive success, which, in large measure, reflects subsistence efficiency: $\mathrm{kcal}$ in/kcal out. For nearly all human evolutionary experience, energy acquisition and expenditure (as PA) have been inextricably linked, but economic growth accompanying the Industrial Revolution disrupted this ancient relationship. During the past two centuries, adjusted per capita income, one measure of subsistence efficiency, has increased 12 -fold in Western nations.

The best current estimates are that the PA of ancestral humans averaged about $1000 \mathrm{kcal} \mathrm{d}^{-1}$ and that their caloric intake was typically about $3000 \mathrm{kcal} \mathrm{d}^{-1}$. Their subsistence efficiency was thus about $3: 1$. In contrast, sedentary humans in contemporary affluent societies commonly consume $2100 \mathrm{kcal} \mathrm{d}^{-1}$ with expenditure, as PA, of perhaps $300 \mathrm{kcal} \mathrm{d}^{-1}$ - a subsistence efficiency of $7: 1$.

With regards to the conference objective, Eaton concluded that evolutionary considerations suggest that increasing energy expenditure, as PA, to re-establish subsistence efficiency of about 3:1 would halt the obesity epidemic and redirect body composition and metabolism towards that ancestral standard for which the human genome was originally selected. A person consuming $2100 \mathrm{kcal} \mathrm{d}^{-1}$ would need an expenditure of $700 \mathrm{kcal} \mathrm{d}^{-1}$ as PA to re-establish the estimated Palaeolithic relationship. If current activity is about $300 \mathrm{kcal} \mathrm{d}^{-1}$, then an additional $400 \mathrm{kcal} \mathrm{d}^{-1}$, an hours aerobic activity or the equivalent, would be required.

\section{Energetic and substrate oxidation aspects of different types of PA}

The energetic aspects of PA was reviewed by van Baak. For most activities, energy expenditure is positively related to body mass. Therefore, energy expenditure during PA is often conveniently expressed as metabolic equivalents (METs), multiples of a standardized resting energy expenditure per kilogram body mass of $1 \mathrm{kcal}(4.18 \mathrm{~kJ}) \mathrm{h}^{-1} \mathrm{~kg}^{-1}$ (or $3.5 \mathrm{~mL} \mathrm{O}_{2} \mathrm{~min}^{-1} \mathrm{~kg}^{-1}$ ), equivalent to the energy expenditure during quiet sitting. Ainsworth et al. have published an extensive compendium of MET values for different 
types of PA, which has been updated recently $(9,10)$. The MET values in the compendium have been derived for average individuals and may be less accurate for obese individuals.

Energy expenditure during non-weight-bearing exercise, such as cycling, at a certain absolute intensity is higher in obese than in normal-weight individuals $(11,12,13,14)$. In the largest study, comparing 225 obese and 81 lean women at a workload of $70 \mathrm{~W}$ on a cycle ergometer, a $16 \%$ higher energy expenditure was found in the obese women (13). In weight-bearing activities such as walking, energy expenditure is also higher in the obese compared with the lean (15). In both non-weight-bearing and weight-bearing activities, the higher energy expenditure may result from the higher fat-free mass, the extra load of moving heavier limbs, and a higher respiratory quotient in the obese.

The consequence of these differences in energy expenditure during activities between lean and obese is that when MET values are applied to estimate energy expenditure, the energy expenditure of the obese will be overestimated during non-weight-bearing activities, because energy expenditure expressed per kilogram body mass during these activities is much lower in the obese than in the lean $(11,12,13,14,16)$. In contrast, during weight-bearing activity, energy expenditure will be underestimated in the obese.

Moderate-intensity exercise is often described as a relative exercise intensity between 40 and $60 \%$ of $V_{\mathrm{O}_{2} \max }$ (5). The absolute intensity (expressed in METs) corresponding with this relative intensity depends on the $V_{\mathrm{O}_{2} \max }$ of the subject. Since the peak oxygen consumption per kilogram body weight of an obese person is usually lower than that of a normal-weight person, the range of MET values corresponding with moderate-intensity exercise is also lower in the obese. A sedentary obese individual, such as typically included in exercise training studies, has an average $V_{\mathrm{O}_{2} \max }$ of around $25 \mathrm{~mL} \mathrm{~min} \mathrm{mg}^{-1}$ (slightly more than 7 METs). Moderate-intensity exercise therefore will correspond with an energy expenditure between 2.8 and 4.3 METs. With $150 \mathrm{~min}$ of moderate-intensity exercise per week, and assuming a body mass of $100 \mathrm{~kg}, 700-1100 \mathrm{kcal}$ of energy will be expended. Weight loss without change in $V_{\mathrm{O}_{2} \max }$ (in $\mathrm{L} \mathrm{min}^{-1}$ ), weekly energy expenditure in PA does not change much. The recent Position Stand of the American College of Sports Medicine on appropriate intervention strategies for weight loss and prevention of weight regain in adults (17) suggests that an energy expenditure over $2000 \mathrm{kcal}^{\text {week }}{ }^{-1}$ may be necessary to prevent weight regain after weight loss. In order to be able to expend that amount of energy within a reasonable time, it is clear that $V_{\mathrm{O}_{2} \max }$ will have to increase as well. Therefore, exercise training accompanying a weight reduction programme is important to increase $V_{\mathrm{O}_{2} \max }$ and thereby enable the reduced-obese individual to expend sufficient amounts of energy with a reasonable time in order to prevent weight regain.
It is often stated that the obese should perform activities of low to moderate intensity in order to attain the highest level of fat oxidation during the active period and thereby positively influence body fat mass loss. This idea is based on two assumptions (1) that fat oxidation is higher during low- than during higher-intensity activities; and (2) that a higher fat oxidation during exercise is, independent of total energy expended, associated with a higher fat mass loss. Total fat oxidation is indeed higher with low-intensity exercise than with higher-intensity exercise if the same amount of energy is expended. However, when performing an exercise bout of the same duration, fat oxidation is similar in low- and higher-intensity exercise (18). With respect to the second assumption, there is no evidence that loss of body fat mass is higher with low-intensity training programmes than with higher-intensity programmes with equal total energy expenditure (19). Loss of fat mass is, as is the case for loss of body mass, positively correlated with weekly energy expenditure (20).

Tremblay reviewed the existing data and came to the conclusion that a regular exposure to the stimulus of vigorous exercise is necessary to affect body weight and composition successfully. The results from the Canada Fitness Survey demonstrated that for a given cost of leisure-time $\mathrm{PA}$, individuals who were performing vigorous (>9 METs) activities on a regular basis were leaner than those exercising at a lower intensity (21). Also in a training study using two levels of exercise intensity, there was a greater subcutaneous fat loss for the high-intensity group despite the lower total energy cost of the programme (22). Furthermore, Imbeault et al. (23) demonstrated that following an exercise bout of $500 \mathrm{kcal}$ either at high- $\left(70-75 \% V_{\mathrm{O}_{2} \max }\right)$ or low-intensity $\left(35-40 \% V_{\mathrm{O}_{2} \max }\right)$, the compensation in ad libitum energy intake was lower after a vigorous exercise. In an additional study with a same experimental approach, post-exercise oxygen consumption and lipid oxidation was higher in the high-intensity exercise bout (24).

\section{Population-based perspectives on PA and weight}

Unfortunately, there are no data available that allow for reliable assessment of the two components of energy balance in large representative populations, especially for PA. There are data for average daily energy intake per capita, from food balance sheet calculations and from surveys of representative samples of individuals. However, there are problems with these data because of changes in food preparation and consumption for the balance sheet data and to under-reporting and inaccurate food composition databases for the individual level surveys. We are unaware of any population level data on average daily energy expenditure. In the absence of such data, it seems reasonable to speculate that daily energy expenditure declined steadily 
during the 20th century, and this trend began to accelerate in the economic expansion after World War II. This was caused by engineering PA out of daily life by increasing mechanization at work, in the home and during leisure time; and in the transition from rural to urban life for the majority of the population in many countries. It may be that the average daily PAL reached a critical point sometime in the $1980 \mathrm{~s}$, perhaps as a result of the telecommunications/computer revolution; and at this point substantial numbers of individuals were not able to regulate their energy balance and began to store the excess calories as fat, leading to the increased prevalence of obesity. This critical PAL is unknown, and is the central point of this Stock Conference.

Di Pietro evaluated the available ecological trend data on PA and weight gain. The hypothesis that PA affects body weight inversely is logical, but observational, populationbased data on the longitudinal relation between these two variables are confusing if not contradictory. Cross-sectional associations between PA or fitness and body weight are stronger than those seen longitudinally, and although there is evidence of an attenuated weight gain in more active individuals, it is not clear that increased PA actually prevents or reverses age-related weight gain at the population level.

There are few surveillance data in representative populations on PA patterns over many years using consistent methods of data collection. Data from the US show a generally stable prevalence of inactivity and a stable prevalence of leisure-time and sports activities from the middle of the 1980s to the mid-1990s (5). Whether or not these data are accurate and given that few data are available over time in most countries around the world, it is important to consider that among the general population, leisure-time PA accounts for a small proportion of the day $(<1 \mathrm{~h})$ and therefore, a small percentage of total daily energy output.

Although population-based trend data on total daily energy expenditure do not exist, consumer data over several years may give useful information about the increasing trends in sedentary behaviour. Using reported data from national monitoring systems, Di Pietro showed US population trends (per capita) in increased automobile use, TV/ VCR sales and viewing, computer and Internet use, increasing legislation in the US eliminating recess from the school day and decreasing physical education requirements over time. All these trends are in favour of a sedentary lifestyle in particular over the last three decades. However, there are several methodological concerns that may explain why we are unable to observe at the population level what can be observed in the laboratory. In particular, the inability to measure accurately the level of PA at a population level gives great difficulties in quantifying the effects of trends in the pattern of PA in the population in relation to the problem of obesity. This is of importance in relation to the other side of the energy balance, namely the trends in energy intake, which also present challenges of consistent and accurate measurement.

Rissanen presented the existing data on prospective studies on PA and weight gain. In Table 1, a summary of prospective studies from different countries with an estimate of the PALs are depicted. From the 13 studies reported, 11 showed an inversed relation between PAL and increase in body mass index (BMI), body fat, weight, or percent overweight/obese. Physical activity level varied from 1.5 to 1.6 for men and 1.4-1.5 for women in the sedentary groups and from 1.6 to $2.0+$ for men and $1.7+$ for women in the high or frequent physically active groups. It was concluded that these data strongly support the importance of an acceptable level of PAL to prevent weight gain. However, from these studies, it is difficult to extract a PAL beyond which weight gain can be prevented. The methodology to measure PA and the design of the studies differ too much to integrate the results to a desired PAL. Data on the measurement of PA by the golden standard doubly labelled water (DLW) method could deliver more precise information about PALs and weight control. Unfortunately, such data are not available on representative populations over time. Westerterp presented the three published metaanalysis of DLW data in relation to obesity. In 1991, Schoeller and Fjeld (25) concluded that obese individuals expend slightly more energy in PA than do the non-obese. Prentice et al. (16) suggested that, except in massive obesity, patterns of PA are quite similar at different levels of BMI. In a later analysis, it was confirmed that the majority of obese subjects is moderately active (26). In addition, a further update of the Maastricht DLW cohort with 278 subjects showed that the PAL of the subjects, calculated by expressing average daily metabolic rate as a multiple of basal metabolic rate $(\mathrm{PAL}=\mathrm{ADMR} / \mathrm{BMR})$, was similar at different levels of BMI as reported by Prentice et al. (16). Physical activity level calculated as the residual of the ADMR$\mathrm{BMR}$ relation was independent of BMI as well. Average daily metabolic rate and non-basal energy expenditure were positively related to body mass where men systematically showed higher values than women at a given body mass, probably as a result of a higher proportion of fatfree mass. Surprisingly, ADMR as well as non-basal energy expenditure were more closely related to fat-free mass than to body mass. The relation was also similar for women and for men. The results suggest the importance of fat-free mass as a determinant of ADMR including PA.

The PAL of a subject as measured with DLW reflects the energy expenditure for PA but not the amount of PA, that is, duration and intensity (16). An alternative method many studies have used to adjust for differences in body size is by expressing non-basal energy expenditure per kilogram body mass, assuming that energy expenditure associated with PA is weight dependent. Schoeller and Jefford investigated this assumption for light activities using DLW 


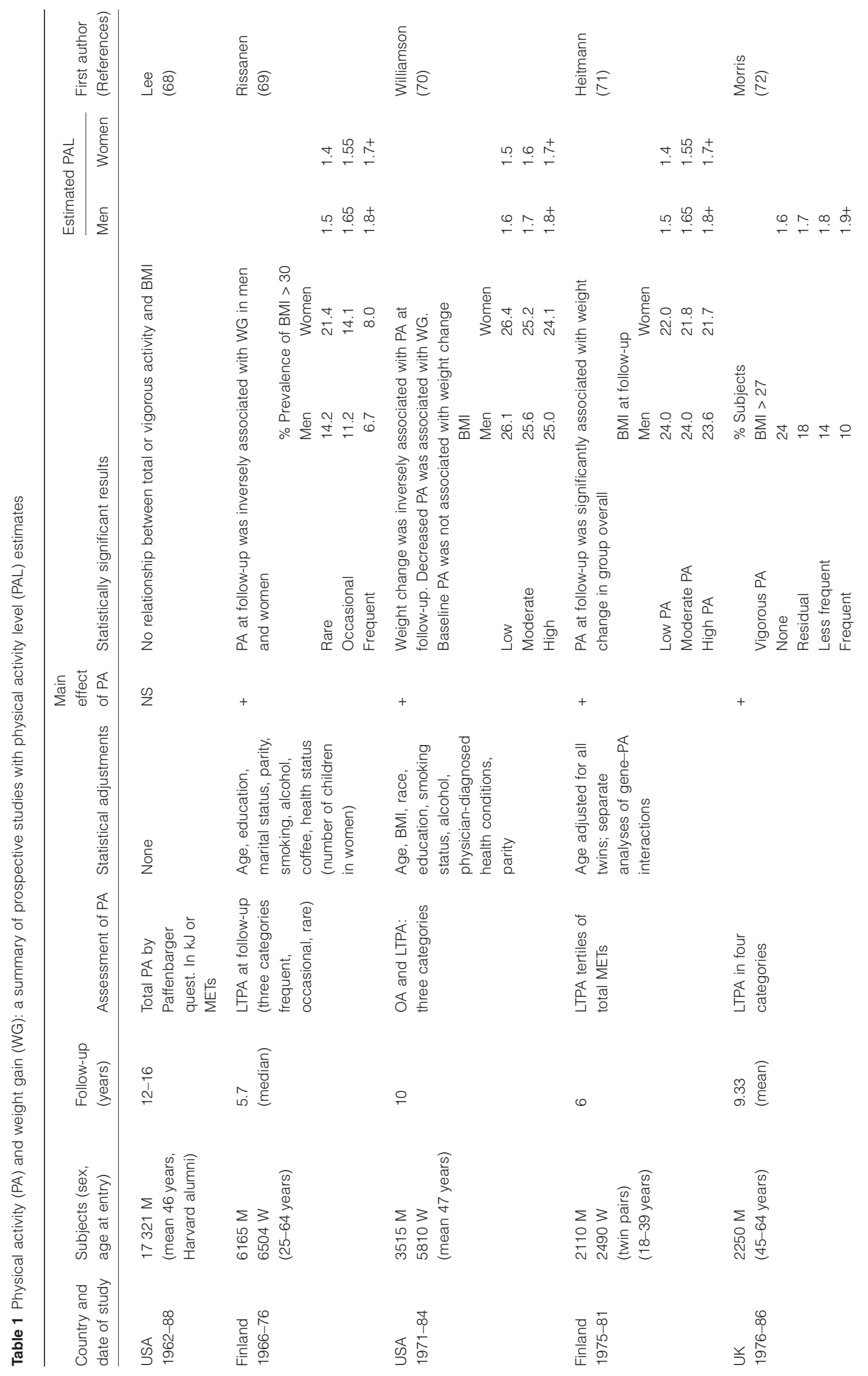




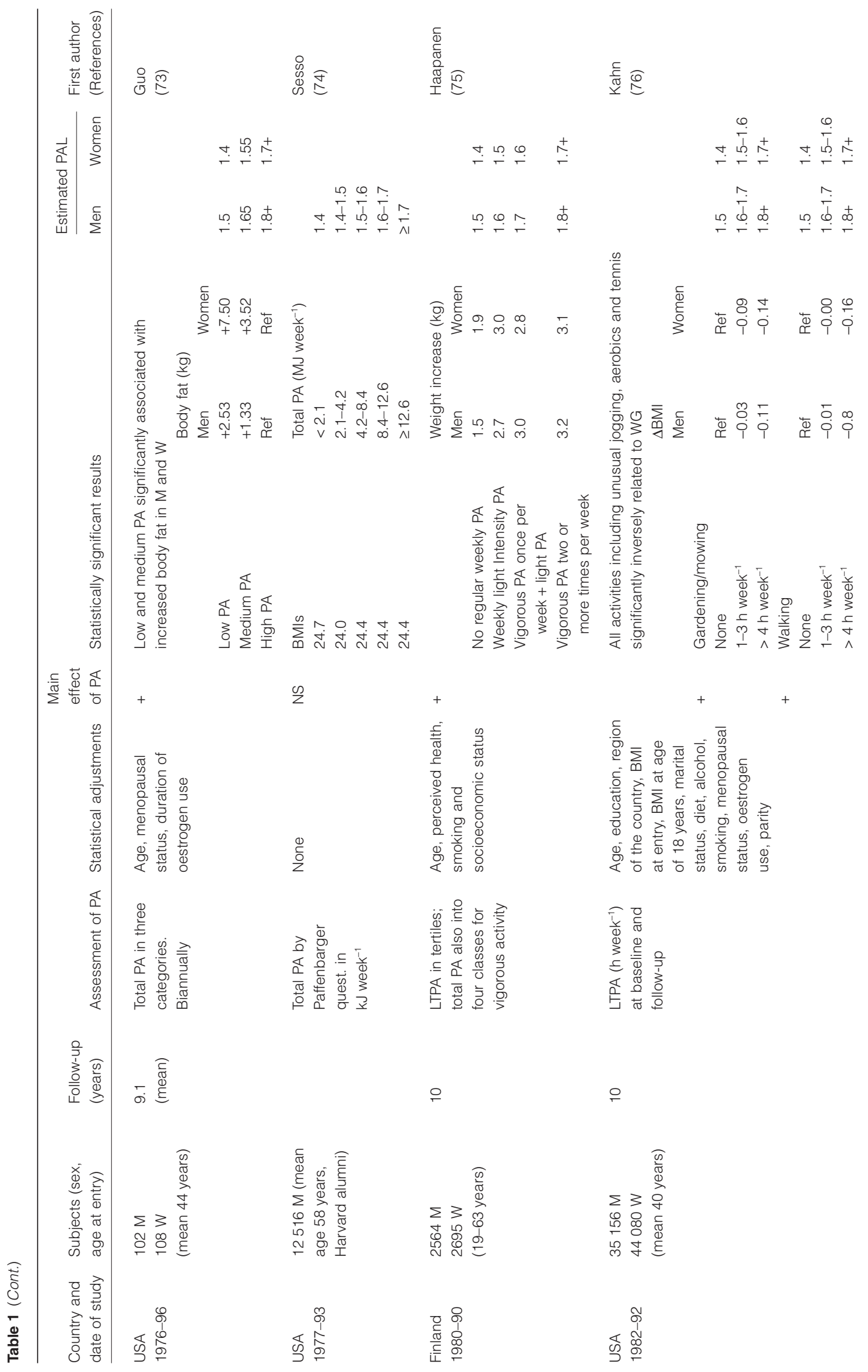




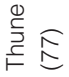

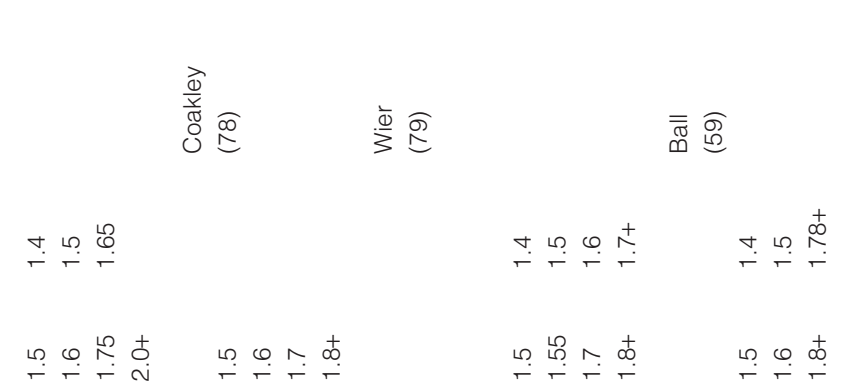

0
0
0
0
0
3
0
0
0
$\frac{\pi}{0}$
0
0
0
0
0

离

ㄴ. ㄴ.

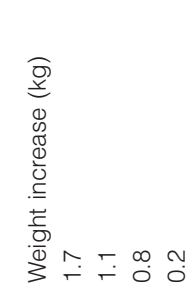

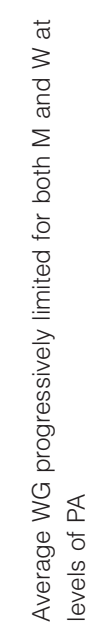

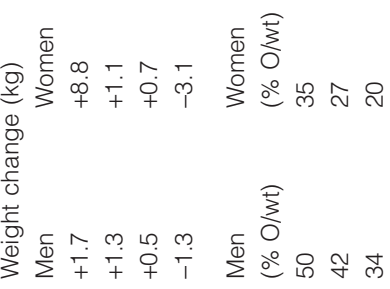

$\overleftarrow{1}$

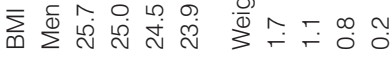

을

兽

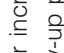

․ㅡㄹ 음

을

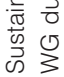
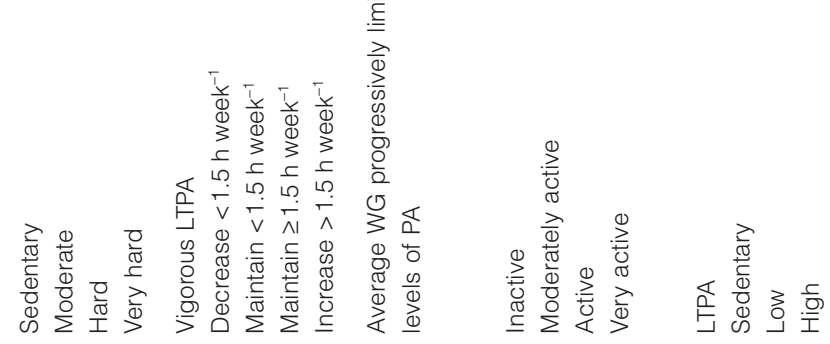

$+$

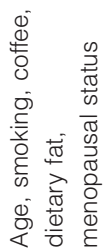

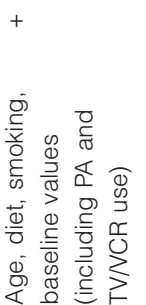

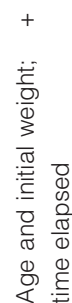

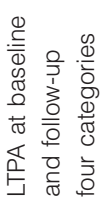

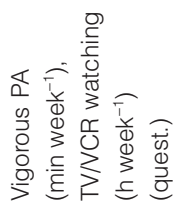

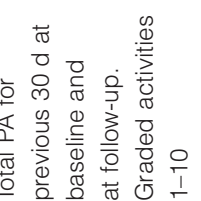

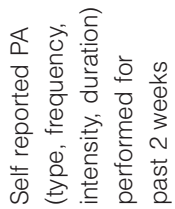

$\wedge$

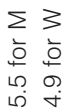

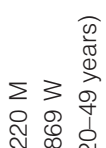

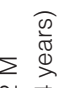

$\checkmark$

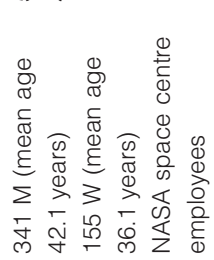

논

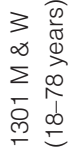

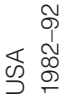

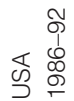

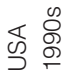

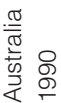


data and came to the conclusion that normalization of energy expenditure of PA by division of body weight is an appropriate means for comparing the volume (intensity $\times$ time) of PA between individuals of different body size (27). Prentice et al. (16) showed that normalizing non-basal energy expenditure by dividing by body mass to the exponent 1.0 (body mass ${ }^{1.0}$ ) over-corrects for body size in heavier people, making them appear less active. They suggested that an exponent close to 0.5 is more appropriate for sedentary lifestyles. The Maastricht database showed a fit of non-basal energy expenditure with body mass with an exponent of 0.41 for women and 0.63 for men. The values were in closer agreement with the suggested value of 0.5 than 1.0. However, it is still questionable whether we thus can conclude that the amount of PA is similar for the obese and the non-obese. Ekelund et al. (28) compared PA as well as movements in obese $(\mathrm{BMI}>30)$ and matched non-obese adolescents where PA was measured with DLW, simultaneously with movement measurements with an accelerometer. The obese performed less movement than the non-obese despite no difference in PAL. Therefore, duration and intensity of PA do not need to be identical with energy spent on activity.

\section{Physical activity during and after weight loss}

Fogelholm and Kukkonen-Harjula reviewed in detail the available data on the effects of PA during and after weight loss based on his published review (29).

It is not very common to use increased PA without diet as the sole technique for weight reduction. However, weight reduction by PA alone is qualitatively very good (almost all weight loss results from fat loss) (30), and the effects of PA on weight reduction, without a concomitant low-energy diet, have indeed been evaluated in a considerable number of studies (for reviews, see 30,31,32,20).

Ballor and Keesey (31) did a meta-analysis including a total of 53 papers, published between 1950 and 1988, with randomized, controlled trials and with data on PA and changes in body composition. Weight reduction programmes were excluded. The average study length was approximately 17 weeks, except for studies with weight training (average duration 10 weeks in males and 12 weeks in females). Males lost $1.3 \mathrm{~kg}$ body weight in trials with running or walking and $1.1 \mathrm{~kg}$ in trials with cycling. The respective fat mass losses were greater for both running/ walking $\left(1.6 \mathrm{~kg}\right.$ or $\left.0.12 \mathrm{~kg} \mathrm{week}^{-1}\right)$ and cycling $(1.9 \mathrm{~kg}$ or $0.11 \mathrm{~kg} \mathrm{week}^{-1}$ ) trials. Weight training resulted in a mean increase in body weight $(1.2 \mathrm{~kg})$, but a reduction in fat mass $(1.0 \mathrm{~kg})$. Results for females were more modest: body mass or fat mass changed significantly only after running/walking $(-0.6$ and $-1.3 \mathrm{~kg}$, respectively), but not after cycling.

In a systematic review, Wing (32) identified 10 studies, published between 1983 and 1995, with comparisons of exercise alone with no treatment in obese subjects. Ross and Janssen (20) completed another review, again including studies with obese subjects, who were randomised into exercise or control (no diet) groups. Combining these two reviews yields 18 studies. In short-term interventions (<26 weeks; $n=8)$, the mean weight reduction was $0.24 \mathrm{~kg} \mathrm{week}^{-1}$ in exercising subjects and $0.05 \mathrm{~kg} \mathrm{week}^{-1}$ in control groups (mean difference $0.19 \mathrm{~kg}$ week $^{-1}$ favouring exercise). Longer-term studies ( $>26$ weeks, $n=10$ ) found only a $0.03-\mathrm{kg}$ body mass reduction in exercising subjects and a $0.01-\mathrm{kg}$ body mass increase in control groups (mean difference $0.04 \mathrm{~kg}$ week $^{-1}$ favouring exercise).

A reduction in energy intake may be regarded as a core method for weight reduction. The additional effects of a concomitant PA programme (most typically aerobic exercise 3-4 times weekly, total training duration 2-4 h week $^{-1}$ ) on weight loss has been studied in several randomised, controlled interventions. A majority of the 19 studies identified by Wing (32) did not show any statistically significant differences between exercise + diet vs. diet only. Nevertheless, when all short-term $(<26$ weeks) studies are pooled, the average weight loss was $0.1 \mathrm{~kg}$ week ${ }^{-1}$ greater in exercising subjects. In longer-term studies ( $>26$ weeks), the mean difference was $0.02 \mathrm{~kg}$ week $^{-1}$ favouring exercising subjects.

Because weight maintenance after weight reduction is more difficult than initial weight loss (33), a systematic review was completed to specifically evaluate the effects of PA on weight loss maintenance (29). There were eight studies with a randomised design and with a prospective follow-up of at least 1-year duration. The duration of weight reduction varied between 8 weeks and 12 months. Three studies used very-low-energy diet during the weight reduction phase, while the other studies used a more conventional diet with restricted energy intake. All studies used aerobic exercise (walking or ergometer cycling) with a target duration of approximately $1.5-3 \mathrm{~h} \mathrm{week}^{-1}$. In addition, Wadden et al. (34) had one group with strength training. The duration of follow-up was usually 1-2 years.

Only one study (35) found clearly that exercise training during weight reduction lead to less weight gain during the follow-up, compared to non-exercising groups. Sikand et al. (36) reported a similar positive, but non-significant trend. King et al. (37) found that weight regain was smallest in exercising subjects randomised to supportive telephone contacts during the follow-up. However, those exercising subjects, who were randomised to no extended support, showed a tendency to regain even more weight than the diet-only subjects did. van Dale et al. (38) reported better weight maintenance in one physical exercise group $(n=5)$, but the finding was apparently caused by one outlier. In contrast to the above results, four studies did not find exercise training to improve maintenance of reduced body weight $(39,40,41,34)$. The weighed mean results of above eight studies suggested that exercise during weight 
reduction slowed weight regain by approximately $0.02 \mathrm{~kg} \mathrm{week}^{-1}(29)$.

\section{PAL recommendations and prevention of weight gain or regain}

The main topic of the conference was to evaluate the current PAL recommendations and the discussion about which PALs can potentially prevent weight gain and regain. Wyatt reviewed the existing recommendation and presented the available data to come to a PAL recommendation.

The US Surgeon General's Report on PA recommends 30 min of moderate-intensity PA on most, preferably all days of the week to improve health (5). This recommendation roughly translates into $150-200 \mathrm{kcal} \mathrm{d}^{-1}$ in energy expenditure depending on a person's body weight. This recommendation is similar to the joint recommendation of 30 min of moderate-intensity activity per day by the Center for Disease Control and Prevention and American College of Sports Medicine in 1995. The World Health Organization recommends a target of a PAL of 1.75 . The PAL of 1.75 would represent an individual whose occupation involves regular PA (or who is a regular exerciser) while a PAL of 1.4 would represent a sedentary individual. For an individual whose resting metabolic rate (RMR) was $1400 \mathrm{kcal} \mathrm{d}^{-1}$, the difference between a PAL of 1.4 and 1.75 equates to an additional $490 \mathrm{kcal} \mathrm{d}^{-1}$, which is considerably more than the $150-200 \mathrm{kcal} \mathrm{d}^{-1}$ based on the $30 \mathrm{~min}$ per day recommendation.

The PA recommendations of the past decade have been based on the desire to improve overall cardiorespiratory fitness and general health and have not been based on the optimal PAL to produce a weight loss or to prevent general weight gain or regain following a loss. A critical piece of recommending a PAL is in the definition of what we want to accomplish (what's the benefit?) and to whom are we making the recommendation (who's the target?). The PAL target for different objectives may in fact be very different. The optimal PAL for producing a weight loss by producing a negative energy balance may differ significantly from the optimal PAL for preventing weight gain across a general population. Additionally, the PAL necessary to maintain energy balance and keep body weight stable in a weight-reduced/obesity-prone individual or population may be substantially different from that for a population that is not prone to obesity or to maintain a healthy weight. Unfortunately, the number of randomised controlled trials directly testing whether or not regular PA can prevent weight gain and how much is required is very limited. In particular, if one wants to qualify the PALs at which the preventive effect acts, only the DLW method can give valuable and accurate answers. So far only a few DLW studies have been published addressing this issue.
Data from epidemiological prospective studies as summarized in Table 1 do indicate a specific level of activity to prevent weight gain over the years. Roughly an increase of 0.25 PAL units can be observed between the sedentary and active groups representing about $350 \mathrm{kcal} \mathrm{d}^{-1}$ or $50-$ 60 min of moderate-intensity PA. However, based on the validity of the PAL estimates in these large-scale population studies, it is difficult to come up with a more precise PAL. In general, the participants agreed on the fact that the existing recommendation of $30 \mathrm{~min}$ per day is most probably not enough to prevent weight gain for many in the general population. However, because of genetic variation and differences in dietary intake, some individuals may avoid weight gain while remaining quite sedentary, and others may be regularly physically active and still gain weight over the middle and later years.

Much more data are available about the desirable PAL for the prevention of weight regain in the reduced obese (see reviews 42,29). Several studies have attempted to quantify the amount or describe the PAL necessary to prevent weight regain following a loss $(43,44,45,46,47)$. However, the methodologies used in many studies provide precise PALs, and the studies using DLW had a cross-sectional design or were too short to thoroughly evaluate the PAweight regain phenomenon. Only in the studies of Schoeller et al. (45) and Weinsier et al. (48) using DLW, validated prospective PAL data could be obtained from women. In the study of Schoeller et al. (45), the active group of reduceobese subjects with a PAL $>1.75$ (mean PAL 1.89) regained the least weight at 1 year following a weight loss when compare to both moderately active (PAL 1.55-1.75) and light activity groups $(\mathrm{PAL}<1.55)$. They estimated the light activity group would have to increase their activity by an additional $3.4 \mathrm{kcal} \mathrm{kg}^{-1} \mathrm{~d}^{-1}$ to achieve the optimal threshold energy expenditure for weight loss maintenance. This corresponds to about $80 \mathrm{~min}$ of moderate activity or $35 \mathrm{~min}$ of vigorous activity added to a sedentary lifestyle.

In the study of Weinsier et al. (48), free-living activity energy expenditure was measured in women successful or unsuccessful at maintaining a normal body weight over a 1-year period. Body weight maintainers $\left(-0.5 \mathrm{~kg} \mathrm{year}^{-1}\right)$ had a PAL of around 1.7 before and after 1 year. In weight gainers $\left(+9.5 \mathrm{~kg} \mathrm{year}^{-1}\right)$ a PAL of 1.55 and 1.60 , respectively, was observed. It was calculated that an additional $4.0 \mathrm{kcal} \mathrm{kg}^{-1} \mathrm{~d}^{-1}$ PA was needed in the weight gain group to match the activity levels in the weight maintenance group representing $77 \mathrm{~min}$ of moderate activity daily or 2.5 -fold that of the current US Surgeon General's recommendation in order to optimize energy balance and to maintain a certain body weight.

In Table 2, both available DLW studies with a long enough follow-up to study weight (re)gain are shown. Both studies indicate that a period of more than $1 \mathrm{~h}$ of moderate PA is necessary to maintain body weight. 
Table 2 Prospective doubly labelled water studies on weight gain and daily physical activity

\begin{tabular}{|c|c|c|c|c|c|c|c|}
\hline \multirow[b]{2}{*}{ Study } & \multirow[b]{2}{*}{ Sex } & \multirow[b]{2}{*}{$\begin{array}{l}\text { Age } \\
\text { (years) }\end{array}$} & \multirow[b]{2}{*}{ Baseline } & \multicolumn{2}{|l|}{ PAL } & \multicolumn{2}{|c|}{ To match active group } \\
\hline & & & & $\begin{array}{l}\text { Activity } \\
\text { groups }\end{array}$ & $\begin{array}{l}\text { Sedentary } \\
\text { groups }\end{array}$ & $\begin{array}{l}\text { Energy expenditure } \\
\left(\mathrm{kcal} \mathrm{kg} \mathrm{d}^{-1}\right)\end{array}$ & $\begin{array}{l}\text { Moderate activity } \\
\text { (min) }\end{array}$ \\
\hline Schoeller et al. 1997 (45) & Female & $20-50$ & $\geq 12 \mathrm{~kg}$ weight loss & 1.89 & 1.45 & 3.4 & 80 \\
\hline Weinsier et al. 2002 (48) & Female & $20-46$ & Weight stable, BMI 27-30 $\mathrm{kg} \mathrm{m}^{-2}$ & 1.73 & 1.60 & 4.0 & 77 \\
\hline
\end{tabular}

PAL, physical activity level; BMI, body mass index.

Cross-sectional data from the National Weight Control Registry (NWCR) support the idea that larger amounts of PA are critical to long-term weight loss success. The NWCR is a registry of over 3000 individuals who have maintained a minimum 30-pound weight loss for at least 1 year. The mean weight loss is 67 pounds. Ninety percent report regular exercise as a critical component in maintaining the loss in long term. The NWCR group reports engaging in $2682 \mathrm{kcal}^{\text {week }}{ }^{-1}$ of PA (44). This is the equivalent of walking approximately 4 miles per day or increasing a PAL of $1.4-1.7$ based on a RMR of $1400 \mathrm{kcal} \mathrm{d}^{-1}$. Data from Jakicic and Wing (43) have also supported a high PAL for maintaining a weight loss in long term. In this study, weight loss at 18 months was significantly greater in the group of subjects who exercised at moderate intensity $>200$ min week $^{-1}$ compared to the $>150$ min group.

Evaluating the available data on PAL and prevention of weight regain in formerly obese individuals, it becomes clear that $60 \mathrm{~min}$ is a minimal estimate but most probably it is closer to $80-90 \mathrm{~min}$ of moderate levels of activities such as walking or cycling.

\section{Physical activity levels for specific groups}

Another important aspect of the conference theme was: who should be targeted with what level of PA? Two specific groups were reviewed and discussed. Davies reviewed the available literature on children-based DLW data. In younger children, the observed total energy expenditure in a number of studies was lower than the recommendations. Fontvieille and colleagues (49) in 1993 assessed total energy expenditure in a group of 28 American children all aged 5 years. The most important finding of the study was that the mean total energy expenditure, being $1370 \mathrm{kcal} \mathrm{d}^{-1}$, was about $24 \%$ below the recommended daily energy allowance. A similar finding was published by Goran and colleagues that same year (50) in a group of children aged 4-6 years. Again the mean total energy expenditure was approximately $25 \%$ below recommendations. The reduction in total energy expenditure in slightly younger children, aged 1.54.5 years, described by Davies et al. (51) was a little less than previously found, being $15 \%$. Nevertheless, these data show quite clearly that in young children total energy expenditure is reduced and that this reduction may well result from a reduction in the energy expended because of PA.

The number of studies in older children are fewer and do not give a clear answer about the desirable PALs in relation to undesirable weight gain. A specific methodological problem is the change of weight in growing children, which makes the normalization for non-basal energy expenditure as described for adults disputable. Therefore, the relationship between PA and obesity is not straightforward as seen in adults.

Physical activity levels in children as young as 6 months has been correlated with percent body fat (52). Similar relationships have been found in older children (53). A recent study (54) showed a significant negative correlation between PALs and percent body fat, BMI and fat mass in boys but, interestingly, not in girls.

More results are available showing that gender differences in PA often appear before puberty with girls spending less time participating in PA and more time in inactive pastimes (55). This is most marked for vigorous PA. For example, Pratt (56) found that $72 \%$ of male high school students reported participating in vigorous PA compared to $54 \%$ of girls. It is fascinating to note that the same gender difference was reported from a meta-analysis of adult data carried out by Westerterp and Goran (57).

The potential gender difference was reviewed in detail by Swinburn. Cross-sectional studies suggest that higher levels of PA are associated with lower BMI and more favourable patterns of body fat distribution $(56,58)$. If the measurement of PA is by self-report, the relationship is often stronger for women $(56,59,60)$. On the other hand, objective measurements with DLW have often found a stronger negative relationship between activity levels and BMI in men than in women (61) or no gender differences (62). Most of the trials of PA on body composition have been either in men or women, making direct comparisons difficult. Very few studies have included men and women in the same trial and reported their results separately. Ballor and Keesey (31) conducted a meta-analysis of studies in 1991 on exercise and fat loss (41 in men and 12 in women). Overall, the average estimated energy expended in running/walking 
programmes for men was $23153 \mathrm{kcal}$ over 16 weeks and for women was $10578 \mathrm{kcal}$ over 13 weeks. The net fat loss was $1.9 \mathrm{~kg}$ in men and $1.3 \mathrm{~kg}$ in women compared to controls. Men expended about twice the energy per session. Only four studies included both genders. Juneau et al. (63) prescribed exercise programmes to achieve $65-77 \%$ maximum heart rate $(345 \mathrm{kcal}$ expenditure per session for men, $235 \mathrm{kcal}$ for women) for $50 \mathrm{~min}$, five times a week for 6 months. Only the men lost weight. Depres et al. (64) similarly prescribed 40 min of exercise to men and women at $80 \%$ maximal heart rate for $4-5 \mathrm{~d}$ a week over 20 weeks. Only men reduced adiposity measured by sum of skinfolds.

Garrow and Summerbell (30) conducted a similar metaanalysis of exercise-only programmes in 1995 and found that, on average, men lost $3.0 \mathrm{~kg}$ in 30 weeks whereas women lost $1.4 \mathrm{~kg}$ in 12 weeks. A review by Votruba et al. (65) of exercise programmes with or without dietary restrictions again only found 3/35 studies that included both men and women and none of them reported genders separately.

Related to the weight regain problem, NWCR (44) of people who have lost a large amount of weight (average $30 \mathrm{~kg}$ ) and maintained a weight loss of at least $13.6 \mathrm{~kg}$ over 5 years provides some insights into the exercise levels needed for weight maintenance after weight loss. Men expended more energy in exercise $\left(3500 \mathrm{kcal}^{\text {week }}{ }^{-1}\right.$ vs. $2650 \mathrm{kcal}^{-1} \mathrm{wee}^{-1}$ in women) to maintain a BMI of $26 \mathrm{~kg} \mathrm{~m}^{-2}$ vs. $24 \mathrm{~kg} \mathrm{~m}^{-2}$ for women. Men engaged in more vigorous PA and preferred more competitive sports and weight lifting compared to women who engaged in lighter exercise and preferred walking and aerobic dancing. Exercise of more than $900 \mathrm{kcal}^{\text {week }}{ }^{-1}$ (about $210 \mathrm{~min}$ of brisk walking) is associated with a $40 \%$ regain of weight, whereas more than $2400 \mathrm{kcal}^{\text {week }}{ }^{-1}$ (about 600 min brisk walking) is associated with less than $15 \%$ regain $(65)$. This high volume of activity may favour men who tend to undertake more vigorous and longer duration PA compared to women $(44,66)$.

Does this mean that separate PA recommendations and guidelines are needed for men and women? The findings suggest that recommendations for PA may need to consider gender differences in the protective effects of activity on weight gain. Physical activity recommendations to individuals need to be tailored to the circumstances of that individual and gender plays a major role at this level as do many other factors such as age, social and economic circumstances, physical limitations, and personal preferences. On the other hand, population-based guidelines cannot afford to take these myriad factors into account, but they do need to be relevant to the individuals. A single guideline is unlikely to achieve this. The Australian PA guidelines were developed through an extensive series of consultations with experts and public groups and they contain four messages (67): 'Think of movement as an opportunity not an inconvenience', 'Be active every day in as many ways as you can', 'Put together at least 30 minutes of moderate-intensity PA on most, preferably all, days', 'If you can, also enjoy some regular, vigorous exercise for extra health and fitness'. While a set of guidelines such as these may be able to accommodate gender and other differences, they have yet to be tested in a broad population promotion.

\section{Consensus statement about the PA recommendations}

As a final task, all participants (see Appendix) took part in an intense discussion to amend a draft consensus statement focusing on the central question of the meeting. The following statement was unanimously accepted.

'The current physical activity guideline for adults of 30 minutes of moderate intensity activity daily, preferably all days of the week, is of importance for limiting health risks for a number of chronic diseases including coronary heart disease and diabetes. However for preventing weight gain or regain this guideline is likely to be insufficient for many individuals in the current environment. There is compelling evidence that prevention of weight regain in formerly obese individuals requires 60-90 minutes of moderate intensity activity or lesser amounts of vigorous intensity activity. Although definitive data are lacking, it seems likely that moderate intensity activity of approximately 45 to 60 minutes per day, or 1.7 PAL is required to prevent the transition to overweight or obesity. For children, even more activity time is recommended. A good approach for many individuals to obtain the recommended level of physical activity is to reduce sedentary behaviour by incorporating more incidental and leisure-time activity into the daily routine. Political action is imperative to effect physical and social environmental changes to enable and encourage physical activity. Settings in which these environmental changes can be implemented include the urban and transportation infrastructure, schools, and workplaces.'

\section{Acknowledgements}

This conference was funded by a grant from Abbott Laboratories. We are grateful to Fiona Scarrott of the IASO office and Kate Baillie, director of IASO, who took care of the organization of this meeting.

\section{References}

1. Bouchard C, Shephard RJ, Stephens T, Sutton JR, McPherson $\mathrm{BD}$. Exercise, fitness and health: a consensus of current knowledge. Human Kinetics: Campaign, IL, 1990. 
2. Bouchard C, Shephard RJ, Stephens T. Physical activity, fitness and health. International proceedings and consensus statement. Human Kinetics: Campaign, IL, 1994.

3. Bouchard C. Physical activity and health: introduction to the dose-response symposium. Med Sci Sports Exerc 2001; 33: S347S350.

4. Pate RR, Pratt M, Blair SN, Haskell WL, Macera CA, Bouchard C, Buchner D, Ettinger W, Heath GW, King AC et al. Physical activity and public health. A recommendation from the Centers for Disease Control and Prevention and the American College of Sports Medicine. JAMA 1995; 273: 402-407.

5. US Department of Health and Human Services. Physical activity and health: A report of the Surgeon General. US Department of Health and Human Services: Atlanta, GA, 1996.

6. US National Institutes of Health, US Department of Health and Human Services. A report of the Surgeon General: physical activity and health at-a-glance. US Department of Health and Human Services: Atlanta, GA, 1996.

7. Institute of Medicine. Dietary reference intake for energy, carbohydrate, fiber, fat, fatty acids, cholesterol, protein and amino acids. Washington National Academic Press 2002; 3: 3-5.

8. Cordain L, Gotshall RW, Eaton SB. Physical activity, energy expenditure and fitness: an evolutionary perspective. Int J Sports Med 1998; 19: 328-335.

9. Ainsworth BE, Haskell WL, Leon AS, Jacobs DR Jr, Montoye HJ, Sallis JF, Paffenbarger RS Jr. Compendium of physical activities: classification of energy costs of human physical activities. Med Sci Sports Exerc 1993; 25: 71-80.

10. Ainsworth BE, Haskell WL, Whitt MC, Irwin ML, Swartz AM, Strath SJ, O’Brien WL, Bassett DR Jr, Schmitz KH, Emplaincourt PO, Jacobs DR Jr, Leon AS. Compendium of physical activities: an update of activity codes and MET intensities. Med Sci Sports Exerc 2000; 32: S498-S504.

11. Andersen RE, Wadden TA. Validation of a cycle ergometry equation for predicting steady-rate $\mathrm{V}_{\mathrm{O}_{2}}$ in obese women. Med Sci Sports Exerc 1995; 27: 1457-1460.

12. Glick Z, Shvartz E. Physiologic responses to exercise in normal and obese women. Int J Obes 1983; 7: 37-44.

13. Hulens M, Vansant G, Lysens R, Claessens AL, Muls E. Exercise capacity in lean versus obese women. Scand J Med Sci Sports 2001; 11: 305-309.

14. Salvadori A, Fanari P, Mazza P, Agosti R, Longhini E. Work capacity and cardiopulmonary adaptation of the obese subject during exercise testing. Chest 1992; 101: 674-679.

15. Foster GD, Wadden TA, Kendrick ZV, Letizia KA, Lander DP, Conill AM. The energy cost of walking before and after significant weight loss. Med Sci Sports Exerc 1995; 27: 888-894. 16. Prentice AM, Goldberg GR, Murgatroyd PR, Cole TJ. Physical activity and obesity: problems in correcting expenditure for body size. Int J Obes Relat Metab Disord 1996; 20: 688-691.

17. Jakicic JM, Clark K, Coleman E, Donnelly JE, Foreyt J, Melanson E, Volek J, Volpe SL. American College of Sports Medicine position stand. Appropriate intervention strategies for weight loss and prevention of weight regain for adults. Med Sci Sports Exerc 2001; 33: 2145-2156.

18. Wilmore JH, Costill DL. Physiology of sport and exercise. Human Kinetics: Campaign, IL, 1994.

19. Duncan JJ, Gordon NF, Scott CB. Women walking for health and fitness. How much is enough? JAMA 1991; 266: 3295-3299.

20. Ross R, Janssen I. Physical activity, total and regional obesity: dose-response considerations. Med Sci Sports Exerc 2001; 33: S521-S527.

21. Tremblay A, Despres JP, Leblanc C, Craig CL, Ferris B, Stephens T, Bouchard C. Effect of intensity of physical activity on body fatness and fat distribution. Am J Clin Nutr 1990; 51: 153157.

22. Tremblay A, Simoneau JA, Bouchard C. Impact of exercise intensity on body fatness and skeletal muscle metabolism. Metabolism 1994; 43: 814-818.

23. Imbeault P, Saint-Pierre S, Almeras N, Tremblay A. Acute effects of exercise on energy intake and feeding behaviour. $\mathrm{Br} J$ Nutr 1997; 77: 511-521.

24. Yoshioka M, Doucet E, St-Pierre S, Almeras N, Richard D, Labrie A, Despres JP, Bouchard C, Tremblay A. Impact of highintensity exercise on energy expenditure, lipid oxidation and body fatness. Int J Obes Relat Metab Disord 2001; 25: 332-339.

25. Schoeller DA, Fjeld CR. Human energy metabolism: what have we learned from the doubly labeled water method? Annu Rev Nutr 1991; 11: 355-373.

26. Westerterp KR. Obesity and physical activity. Int J Obes Relat Metab Disord 1999; 23: 59-64.

27. Schoeller DA, Jefford G. Determinants of the energy costs of light activities: inferences for interpreting doubly labeled water data. Int J Obes Relat Metab Disord 2002; 26: 97-101.

28. Ekelund U, Aman J, Yngve A, Renman C, Westerterp K, Sjostrom M. Physical activity but not energy expenditure is reduced in obese adolescents: a case-control study. Am J Clin Nutr 2002; 76: 935-941.

29. Fogelholm M, Kukkonen-Harjula K. Does physical activity prevent weight gain - a systematic review. Obes Rev 2000; 1: 95111.

30. Garrow JS, Summerbell CD. Meta-analysis: effect of exercise, with or without dieting, on the body composition of overweight subjects. Eur J Clin Nutr 1995; 49: 1-10.

31. Ballor DL, Keesey RE. A meta-analysis of the factors affecting exercise-induced changes in body mass, fat mass and fat-free mass in males and females. Int J Obes 1991; 15: 717-726.

32. Wing RR. Physical activity in the treatment of the adulthood overweight and obesity: current evidence and research issues. Med Sci Sports Exerc 1999; 31: S547-S552.

33. Jeffery RW, Drewnowski A, Epstein LH, Stunkard AJ, Wilson GT, Wing RR, Hill DR. Long-term maintenance of weight loss: current status. Health Psychol 2000; 19: 5-16.

34. Wadden TA, Vogt RA, Foster GD, Anderson DA. Exercise and the maintenance of weight loss: 1-year follow-up of a controlled clinical trial. J Consult Clin Psychol 1998; 66: 429433.

35. Pavlou KN, Krey S, Steffee WP. Exercise as an adjunct to weight loss and maintenance in moderately obese subjects. Am J Clin Nutr 1989; 49: 1115-1123.

36. Sikand G, Kondo A, Foreyt JP, Jones PH, Gotto AM Jr. Twoyear follow-up of patients treated with a very-low-calorie diet and exercise training. J Am Diet Assoc 1988; 88: 487-488.

37. King AC, Frey-Hewitt B, Dreon DM, Wood PD. Diet vs exercise in weight maintenance. The effects of minimal intervention strategies on long-term outcomes in men. Arch Intern Med 1989; 149: 2741-2746.

38. van Dale D, Saris WH, ten Hoor F. Weight maintenance and resting metabolic rate $18-40$ months after a diet/exercise treatment. Int J Obes 1990; 14: 347-359.

39. Perri MG, McAdoo WG, McAllister DA, Lauer JB, Yancey DZ. Enhancing the efficacy of behavior therapy for obesity: effects of aerobic exercise and a multicomponent maintenance program. J Consult Clin Psychol 1986; 54: 670-675.

40. Skender ML, Goodrick GK, Del Junco DJ, Reeves RS, Darnell L, Gotto AM, Foreyt JP. Comparison of 2-year weight loss trends in behavioral treatments of obesity: diet, exercise, and combination interventions. J Am Diet Assoc 1996; 96: 342-346. 
41. Wing RR, Venditti E, Jakicic JM, Polley BA, Lang W. Lifestyle intervention in overweight individuals with a family history of diabetes. Diabetes Care 1998; 21: 350-359.

42. Pronk NP, Wing RR. Physical activity and long-term maintenance of weight loss. Obes Res 1994; 2: 587-599.

43. Jakicic JM, Winters C, Lang W, Wing RR. Effects of intermittent exercise and use of home exercise equipment on adherence, weight loss, and fitness in overweight women: a randomized trial. JAMA 1999; 282: 1554-1560.

44. Klem ML, Wing RR, McGuire MT, Seagle HM, Hill JO. A descriptive study of individuals successful at long-term maintenance of substantial weight loss. Am J Clin Nutr 1997; 66: 239246.

45. Schoeller DA, Shay K, Kushner RF. How much physical activity is needed to minimize weight gain in previously obese women? Am J Clin Nutr 1997; 66: 551-556.

46. Weinsier RL, Hunter GR, Desmond RA, Byrne NM, Zuckerman PA, Darnell BE. Free-living activity energy expenditure in women successful and unsuccessful at maintaining a normal body weight. Am J Clin Nutr 2002; 75: 499-504.

47. Wing RR, Hill JO. Successful weight loss maintenance. Annu Rev Nutr 2001; 21: 323-341.

48. Weinsier RL, Hunter GR, Schutz Y, Zuckerman PA, Darnell BE. Physical activity in free-living, overweight white and black women: divergent responses by race to diet-induced weight loss. Am J Clin Nutr 2002; 76: 736-742.

49. Fontvieille AM, Harper IT, Ferraro RT, Spraul M, Ravussin E. Daily energy expenditure by five-year-old children, measured by doubly labeled water. J Pediatr 1993; 123: 200-207.

50. Goran MI, Carpenter WH, Poehlman ET. Total energy expenditure in 4- to 6-yr-old children. Am J Physiol 1993; 264: E706E711.

51. Davies PS, Gregory J, White A. Energy expenditure in children aged 1.5 to 4.5 years: a comparison with current recommendations for energy intake. Eur J Clin Nutr 1995; 49: 360-364.

52. Li R, O'Connor L, Buckley D, Specker B. Relation of activity levels to body fat in infants 6 to 12 months of age. J Pediatr 1995; 126: 353-357.

53. Davies PS, Gregory J, White A. Physical activity and body fatness in pre-school children. Int J Obes Relat Metab Disord 1995; 19: 6-10.

54. Ball EJ, O'Connor J, Abbott R, Steinbeck KS, Davies PS, Wishart C, Gaskin KJ, Baur LA. Total energy expenditure, body fatness, and physical activity in children aged 6-9 y. Am J Clin Nutr 2001; 74: 524-528.

55. Goran MI, Gower BA, Nagy TR, Johnson RK. Developmental changes in energy expenditure and physical activity in children: evidence for a decline in physical activity in girls before puberty. Pediatrics 1998; 101: 887-891.

56. Pratt M, Macera CA, Blanton C. Levels of physical activity and inactivity in children and adults in the United States: current evidence and research issues. Med Sci Sports Exerc 1999; 31: S526-S533.

57. Westerterp KR, Goran MI. Relationship between physical activity related energy expenditure and body composition: a gender difference. Int J Obes Relat Metab Disord 1997; 21: 184-188. 58. Di Pietro L. Physical activity, body weight, and adiposity: an epidemiologic perspective. Exerc Sport Sci Rev 1995; 23: 275-303. 59. Ball K, Owen N, Salmon J, Bauman A, Gore CJ. Associations of physical activity with body weight and fat in men and women. Int J Obes Relat Metab Disord 2001; 25: 914-919.

60. Salmon J, Owen N, Bauman A, Schmitz MK, Booth M. Leisure-time, occupational, and household physical activity among professional, skilled, and less-skilled workers and homemakers. Prev Med 2000; 30: 191-199.
61. Ferro-Luzzi A, Martino L. Obesity and physical activity. Ciba Found Symp 1996; 201: 207-221; discussion 221-227.

62. Prentice AM, Black AE, Coward WA, Cole TJ. Energy expenditure in overweight and obese adults in affluent societies: an analysis of 319 doubly-labelled water measurements. Eur J Clin Nutr 1996; 50: 93-97.

63. Juneau M, Rogers F, De Santos V, Yee M, Evans A, Bohn A, Haskell WL, Taylor CB, DeBusk RF. Effectiveness of selfmonitored, home-based, moderate-intensity exercise training in middle-aged men and women. Am J Cardiol 1987; 60: 66-70.

64. Depres JP, Bouchard C, Savard R, Tremblay A, Marcotte M, Theriault G. The effect of a 20 -week endurance training program on adipose-tissue morphology and lipolysis in men and women. Metabolism 1984; 33: 235-239.

65. Votruba SB, Horvitz MA, Schoeller DA. The role of exercise in the treatment of obesity. Nutrition 2000; 16: 179-188.

66. Dunn AL, Garcia ME, Marcus BH, Kampert JB, Kohl HW, Blair SN. Six-month physical activity and fitness changes in Project Active, a randomized trial. Med Sci Sports Exerc 1998; 30: 10761083.

67. Egger G, Donovan RJ, Corti B, Bull FC, Swinburn BS. Developing national physical activity guidelines for Australians. Aust N Z J Public Health 2001; 25: 561-563.

68. Lee IM, Manson JE, Hennekens CH, Paffenbarger RS Jr. Body weight and mortality. A 27-year follow-up of middle-aged men. JAMA 1993; 270: 2823-2828.

69. Rissanen AM, Heliovaara M, Knekt P, Reunanen A, Aromaa A. Determinants of weight gain and overweight in adult Finns. Eur J Clin Nutr 1991; 45: 419-430.

70. Williamson DF, Madans J, Anda RF, Kleinman JC, Kahn HS, Byers T. Recreational physical activity and ten-year weight change in a US national cohort. Int J Obes Relat Metab Disord 1993; 17: 279-286.

71. Heitmann BL, Kaprio J, Harris JR, Rissanen A, Korkeila M, Koskenvuo M. Are genetic determinants of weight gain modified by leisure-time physical activity? A prospective study of Finnish twins. Am J Clin Nutr 1997; 66: 672-678.

72. Morris JN, Clayton DG, Everitt MG, Semmence AM, Burgess $\mathrm{EH}$. Exercise in leisure time: coronary attack and death rates. $\mathrm{Br}$ Heart J 1990; 63: 325-334.

73. Guo SS, Zeller C, Chumlea WC, Siervogel RM. Aging, body composition, and lifestyle: the Fels Longitudinal Study. Am J Clin Nutr 1999; 70: 405-411.

74. Sesso HD, Paffenbarger RS Jr, Lee IM. Physical activity and coronary heart disease in men. The Harvard Alumni Health Study Circulation 2000; 102: 975-980.

75. Haapanen N, Miilunpalo S, Pasanen M, Oja P, Vuori I. Association between leisure time physical activity and 10-year body mass change among working-aged men and women. Int $J$ Obes Relat Metab Disord 1997; 21: 288-296.

76. Kahn HS, Tatham LM, Rodriguez C, Calle EE, Thun MJ, Heath CW Jr. Stable behaviors associated with adults' 10-year change in body mass index and likelihood of gain at the waist. Am J Public Health 1997; 87: 747-754.

77. Thune I, Njolstad I, Lochen ML, Forde OH. Physical activity improves the metabolic risk profiles in men and women: the Tromso Study. Arch Intern Med 1998; 158: 1633-1640.

78. Coakley EH, Rimm EB, Colditz G, Kawachi I, Willett W. Predictors of weight change in men: results from the Health Professionals Follow-up Study. Int J Obes Relat Metab Disord 1998; 22: 89-96.

79. Wier LT, Ayers GW, Jackson AS, Rossum AC, Poston WS, Foreyt JP. Determining the amount of physical activity needed for long-term weight control. Int J Obes Relat Metab Disord 2001; 25: 613-621. 


\section{Appendix: participants list}

\begin{tabular}{|c|c|}
\hline A. Astrup & $\begin{array}{l}\text { The Research Department of Human Nutrition, Royal Veterinary \& Agricultural University, } \\
\text { Frederiksberg, Denmark }\end{array}$ \\
\hline L.-M. Atkin & $\begin{array}{l}\text { Children's Nutrition Research Centre, Department of Paediatrics and Child Health, Univer- } \\
\text { ity of Queensland, Brisbane, Australia }\end{array}$ \\
\hline M. van Baak & $\begin{array}{l}\text { Nutrition and Toxicology Research Institute Maastricht, Department of Human Biology, } \\
\text { Maastricht University, the Netherlands }\end{array}$ \\
\hline S.N. Blair & Cooper Institute, Dallas, Texas \\
\hline I. Caterson & uman Nutrition Unit, Department of Biochemistry, University of Sydney, Australia \\
\hline P.S.W. Davies & $\begin{array}{l}\text { Children's Nutritional Research Centre, Department of Paediatrics and Children Health, } \\
\text { University of Queensland, Royal Children's Hospital, Brisbane, Australia }\end{array}$ \\
\hline B. Deforce & School of Movement Studies, Queensland University of Technology, Brisbane, Australia \\
\hline L. Di Pietro & he John B Pierce Laboratory, Yale University, New Haven, USA \\
\hline D. Dunstan & nternational Diabetes Institute, Caulfield, Australia \\
\hline J. Dziura & John B Pierce Laboratory, Yale School of Epidemiology and Public Health, USA \\
\hline S.B. Eaton & Emory University School of Medicine, Atlanta, USA \\
\hline J. Erlichman & /o International Obesity TaskForce, London, UK \\
\hline E. (Stock) Evans & 9, Kendrick Mews, London SW73HG, UK \\
\hline M. Fogelholm & he UKK Institute for Health Promotion Research, Tampere, Finland \\
\hline P. Gately & chool of Leisure \& Sports Studies, Leeds Metropolitan University, UK \\
\hline B. Heitmann & $\begin{array}{l}\text { Research Unit for Dietary Studies, Institute of Preventive Medicine, Copenhagen University } \\
\text { Hospital, Denmark }\end{array}$ \\
\hline V. Kantarataanakul & $\begin{array}{l}\text { Cardiac Rehabilitation Unit, Department of Rehabilitation Medicine, Mahidol University, } \\
\text { Thailand }\end{array}$ \\
\hline K. Kijboonchoo & hysiological Nutrition Division, institute of Nutrition, Mahidol University, Thailand \\
\hline N. King & \\
\hline G. Tin-Choi Ko & $1+1$ \\
\hline W. var & $\begin{array}{l}\text { Institute for Research in Extramural Medicine and Department of Social Medicine, Vrije } \\
\text { Universiteit Amsterdam, the Netherlands }\end{array}$ \\
\hline M.I. Noor & $\begin{array}{l}\text { Department of Nutrition \& Dietetics Faculty of Allied Health Sciences, University Kebang- } \\
\text { saan, Malaysia }\end{array}$ \\
\hline C. Pongurgsorn & dicine, Siriraj Hospital, Bangkok, Thailand \\
\hline E. va & Pascal, \\
\hline T. Rankinen & ton Biomedical Research Center, Louisiana, USA \\
\hline A. Rissanen & Obesity Research Unit, Helsinki University Hospital, Finland \\
\hline P. Ruckpanich & Rehabilitation Department, Lerdsin General Hospital, Bangkok, Thailand \\
\hline W.H.M. Saris & $\begin{array}{l}\text { Nutrition and Toxicology Research Institute Maastricht, Department of Human Biology, } \\
\text { Maastricht University, the Netherlands }\end{array}$ \\
\hline D.A. S & Nutritional Sciences, University of Wisconsin, USA \\
\hline B. Swinburn & School of Health Sciences, Deakin University, Melbourne, Australia \\
\hline S. Toubro & $\begin{array}{l}\text { The Research Department of Human Nutrition, Royal Veterinary and Agricultural University, } \\
\text { Frederiksberg, Denmark }\end{array}$ \\
\hline A. Tremblay & f Kinesiology, Laval University, Québec, Canada \\
\hline R. Weiland & linois, USA \\
\hline K.R. Westerterp & $\begin{array}{l}\text { Nutrition and Toxicology Research Institute Maastricht, Department of Human Biology, } \\
\text { Maastricht University, the Netherlands }\end{array}$ \\
\hline M. Westerterp-Plantenga & $\begin{array}{l}\text { Nutrition and Toxicology Research Institute Maastricht, Department of Human Biology, } \\
\text { Maastricht University, the Netherlands }\end{array}$ \\
\hline H. Wyatt & University of Colorado Health Sciences Center, Center for Human Nutrition, Denver, USA \\
\hline D. York & ennington Biomedical Research Center, Louisiana State University, USA \\
\hline
\end{tabular}

Pennington Biomedical Research Center, Louisiana State University, USA 